\title{
Impacts of European drought events: insights from an international database of text-based reports
}

\author{
Kerstin Stahl $^{1}$, Irene Kohn ${ }^{1}$, Veit Blauhut ${ }^{1}$, Julia Urquijo ${ }^{2}$, Lucia De Stefano ${ }^{2}$, Vanda Acácio ${ }^{3}$, Susana Dias ${ }^{3}$, \\ James H. Stagge ${ }^{4}$, Lena M. Tallaksen ${ }^{4}$, Eleni Kampragou ${ }^{5}$, Anne F. Van Loon ${ }^{6, a}$, Lucy J. Barker ${ }^{7}$, Lieke A. Melsen $^{6}$, \\ Carlo Bifulco $^{3}$, Dario Musolino ${ }^{8}$, Alessandro de Carli ${ }^{8}$, Antonio Massarutto ${ }^{8,9}$, Dionysis Assimacopoulos ${ }^{5}$, and \\ Henny A. J. Van Lanen ${ }^{6}$ \\ ${ }^{1}$ Hydrology Department, University of Freiburg, Freiburg, Germany \\ ${ }^{2}$ Geodynamics Department, Complutense University of Madrid, Madrid, Spain \\ ${ }^{3}$ Centre for Applied Ecology "Prof. Baeta Neves", School of Agriculture, University of Lisbon, Lisbon, Portugal \\ ${ }^{4}$ Dept. of Geosciences, University of Oslo, Oslo, Norway \\ ${ }^{5}$ School of Chemical Engineering, National Technical University of Athens, Athens, Greece \\ ${ }^{6}$ Hydrology and Quantitative Water Management Group, Wageningen University, Wageningen, the Netherlands \\ ${ }^{7}$ Centre for Ecology and Hydrology, Wallingford, UK \\ ${ }^{8}$ Center for Research on Regional Economics, Transport and Tourism, Bocconi University, Milan, Italy \\ ${ }^{9}$ Department of Economics and Statistics, University of Udine, Udine, Italy \\ anow at: School of Geography, Earth \& Environmental Sciences, University of Birmingham, Birmingham, UK
}

Correspondence to: Kerstin Stahl (kerstin.stahl@hydrology.uni-freiburg.de)

Received: 14 August 2015 - Published in Nat. Hazards Earth Syst. Sci. Discuss.: 8 September 2015

Revised: 7 February 2016 - Accepted: 23 February 2016 - Published: 21 March 2016

\begin{abstract}
Drought is a natural hazard that can cause a wide range of impacts affecting the environment, society, and the economy. Providing an impact assessment and reducing vulnerability to these impacts for regions beyond the local scale, spanning political and sectoral boundaries, requires systematic and detailed data regarding impacts. This study presents an assessment of the diversity of drought impacts across Europe based on the European Drought Impact report Inventory (EDII), a unique research database that has collected close to 5000 impact reports from 33 European countries. The reported drought impacts were classified into major impact categories, each of which had a number of subtypes. The distribution of these categories and types was then analyzed over time, by country, across Europe and for particular drought events. The results show that impacts on agriculture and public water supply dominate the collection of drought impact reports for most countries and for all major drought events since the 1970s, while the number and relative fractions of reported impacts in other sectors can vary regionally and from event to event. The analysis also shows that reported impacts have increased over time as more media
\end{abstract}

and website information has become available and environmental awareness has increased. Even though the distribution of impact categories is relatively consistent across Europe, the details of the reports show some differences. They confirm severe impacts in southern regions (particularly on agriculture and public water supply) and sector-specific impacts in central and northern regions (e.g., on forestry or energy production). The protocol developed thus enabled a new and more comprehensive view on drought impacts across Europe. Related studies have already developed statistical techniques to evaluate the link between drought indices and the categorized impacts using EDII data. The EDII is a living database and is a promising source for further research on drought impacts, vulnerabilities, and risks across Europe. A key result is the extensive variety of impacts found across Europe and its documentation. This insight can therefore inform drought policy planning at national to international levels. 


\section{Introduction}

Much progress has been made since Wilhite and Glantz (1985) criticized the drought research community for a disproportionate research focus on climate and hydrology, while not sufficiently incorporating the economic, political, and other human aspects that affect this hazard. It is now accepted that a purely natural sciences perspective is not capable of capturing the multi-faceted impacts of drought (Kallis, 2008; Lackstrom et al., 2013). An assessment of past drought impacts is a crucial step in developing measures to reduce vulnerability against drought hazard (Knutson et al., 1998; Wilhite et al., 2000; Wilhite et al., 2007; UN/ISDR, 2009). Systematic quantitative knowledge on the environmental and socioeconomic impacts of drought, however, is often the missing piece in drought planning and management. According to Hayes et al. (2011), there "appears to be a fundamental lack of knowledge or understanding about the importance of monitoring impacts, the usefulness of impact information, and the type of information that is worthwhile to collect". As a result, large-scale studies related to drought monitoring, early-warning, drought planning, and policy development often do not incorporate information on societal drought impacts; the drought indicators typically are chosen arbitrarily and not linked to specific impacts (Wilhite, 2000; Kallis, 2008; Lackstrom et al., 2013; Steinemann, 2014).

The monitoring and assessment of drought impacts is complex because different types of impacts vary in their intensity, often in different phases of the given drought event. Most empirical studies of drought impacts have focused on agricultural crop production, which is direct, immediately observable, well understood, and easy to quantify (Wilhite, 2000; Ding et al., 2011). Lackstrom et al. (2013) concluded that there was a lack of data and understanding of impacts on sectors other than agriculture and water resources. Studies of cross-sectoral drought impacts are generally limited by data availability, as impact data is often maintained by different organizations, e.g., agriculture, fisheries, and hydropower statistics are rarely housed by the same department. Moreover, in-depth case studies may be very useful in the context of the specific sector and region they are focused on, yet they are methodologically heterogeneous and rarely cross-comparable (Kallis, 2008). In the USA, the National Drought Mitigation Center (NMDC, drought.unl.edu) has considerable interest and experience in the collection and use of trans-regional and trans-sectoral drought impact reports. Their Drought Impact Reporter (DIR) tool is used in nearreal time as part of the monitoring and early-warning system (droughtreporter.unl.edu; Wilhite et al., 2007; Dieker et al., 2010; Lackstrom et al., 2013). For example, the collected impact information supports expert judgement that contributes to the drought severity classification for the weekly release of the US Drought Monitor map (http://www.droughtmonitor. unl.edu).
In an international setting such as in the European Union, which also spans different geo-climatic regions, a transboundary, and trans-sectoral assessment of drought impacts is particularly important. A number of databases exist that collect statistics on elements affected by drought: crop yield, hydropower production, wildfires, or various aspects of water resources (e.g., Eurostat: epp.eurostat.ec.europa.eu/; European Forest Fire Information System (EFFIS), http://forest. jrc.ec.europa.eu/effis/; Water Information System for $\mathrm{Eu}-$ rope (WISE): water.europa.eu/). However, these statistics do not make an assignment of cause (drought) and effect (the statistics). The unambiguous attribution of a reported loss in a particular season, year, or multi-year period to a particular causing drought event requires additional information to isolate the drought cause from complex and sometimes competing extraneous factors. Information on impacts that are directly linked to drought is often available in regional or national reports of environment agencies, in newsletters from stakeholders such as agricultural associations, in the media, or even from personal observation in the field. In Europe, however, such textual evidence has found limited application in drought impact analysis on a larger scale (beyond national boundaries).

The European Union and the European Environment Agency have identified the need to assemble information on a number of natural hazards, including drought (European Commission, 2012; European Environment Agency, 2011, 2012; Kossida et al., 2012). Because of the trans-boundary impacts of large-scale drought in Europe and the transnational data sharing challenges inherent in the European Union, the development of a comprehensive drought impact database is particularly important for Europe. In support of this request, this study demonstrates the potential of a novel database of categorized drought impact reports for Europe that was developed within the EU FP-7 project DROUGHTR\&SPI (http://www.eu-drought.org). Specifically, it aims to

- evaluate the availability of drought impact information and the challenges in categorizing drought impact reports across sectors,

- analyze emerging patterns of reported drought impacts in time, space and categories across Europe's geoclimatic regions, and

- assess pathways to capitalize on this information, considering the limitations discovered by the analyses.

\section{The European Drought Impact report Inventory (EDII): database structure, status, and assessment}

As commonly encountered with drought research (Smakthin and Schipper, 2008), there is no consistently used standard terminology and classification for drought impacts and 
related economic losses (Kallis, 2008; Logar and van den Bergh, 2013). The impacts of drought are often classified either into the categories "economic", "environmental", and "social", or into "direct", "indirect", and "intangible", which refers to non-market losses (e.g., Wilhite and Vanyarkho, 2000; Ding et al., 2011; Logar and van den Bergh, 2013; Gil et al., 2013). Knutson et al. (1998) defined drought impacts as specific effects of drought, which are symptoms of vulnerability. Using this definition of drought impact, the EDII database aims to compile reports on negative environmental, economic or social effects experienced as a consequence of drought. Its impact categorization scheme is tailored to capture the most directly observable impacts across a wide range of sectors.

The EDII is structured into five primary sections that include the following information on the reported impact: (1) reference, (2) location, (3) timing, (4) description, and (5) secondary impacts/response measures (Stahl et al., 2012). Each drought impact report entered into the database must provide the following information on items $1-4$, with item 5 being optional.

1. Impact reference must be entered, including the type of source (Table A1), author, year, title, and weblink (where applicable). Information on the reported impact entered into the database should closely reflect the reference and thus be traceable and reproducible.

2. Location of reported impact must be entered, with at least the country level and options to refer either to different levels of geographical regions using the European Union NUTS (Nomenclature of Territorial Units for Statistics) regions standard or to specific rivers and lakes.

3. Timing of reported impact must be entered, with at least the year, but preferably a specification of the season or month of occurrence, and, if possible, a link to a major regional drought event listed in the database.

4. Impact category and sub-type(s) according to the classification in Table A2 as well as a short (free) text description must be entered. This text description should reflect the text of the original information source as closely as possible. Contributors provide this summary in English, regardless of the language of the original reports.

5. Associated secondary impacts, response and mitigation measures, and other relevant information that may be available can be entered. This information is optional because information on response measures directly associated with the particular reported impact are rarely available from the same report. The unique reference to the reported impact, however, is a requirement for the database's scheme of operating by "impact report". An independent collection of measures (not linked to the respectively reported impacts) would require tapping different sources, a different coding logic and database structure and was not in the scope of this study.

Unlike efforts that rely mostly on popular press and news coverage to target real-time occurrence of drought impacts (e.g., the European Media Monitor used by the European Drought Observatory of the Joint Research Centre of the European Commission http://edo.jrc.ec.europa.eu), the EDII database was established for historical drought analysis within a multi-national research project. It incorporates these sources as well, but in order to collect data from past decades, it relies more heavily on scientific and governmental sources, including published regular or special reports in European native languages, theses, scientific articles, and other such sources.

A website interface (http://www.geo.uio.no/edc/ droughtdb/) has been developed with pull-down menus to facilitate the submission and categorization of impact reports. This interface allows the submission of impact data into an SQL (structured query language) database. Submissions are only transferred into the database after screening by the database team. The database can be queried through the same web interface. At present it includes over 1200 unique references (original sources), which have resulted in over 4700 drought impact reports, i.e., database entries. We refer to these as "impact report" entries. A given impact report entry made for one of the 15 "impact categories" can then contain reference to several impacts that can further be assigned to different "impact type" subcategories (Table A2). The approximately 4700 impact report entries thus resulted in over 6900 individual impacts that are now classified by both their impact category and their impact type subcategory. We refer to these as "reported impacts".

The resulting categorical data can then be analyzed and summarized in a number of ways. The overview presented herein is based on an analysis of reported drought impacts as classified and categorized in the EDII. First, we analyzed the overall content of the database in terms of the

- spatial and temporal distribution of the number of impact report entries and their sources, and the

- distribution of reported impact categories and impact types for particular geographical regions and over time.

Second, we investigated selected historical (reference) drought events in Europe with respect to the distribution of reported impact categories and the impacts' text descriptions. Unfortunately, only a limited number of entries have associated information on secondary impacts or response measures in time and space at the scales of interest in the paper (long period of time, pan-Europe), thus preventing an analysis of these aspects given the current content of the database. 
(a)
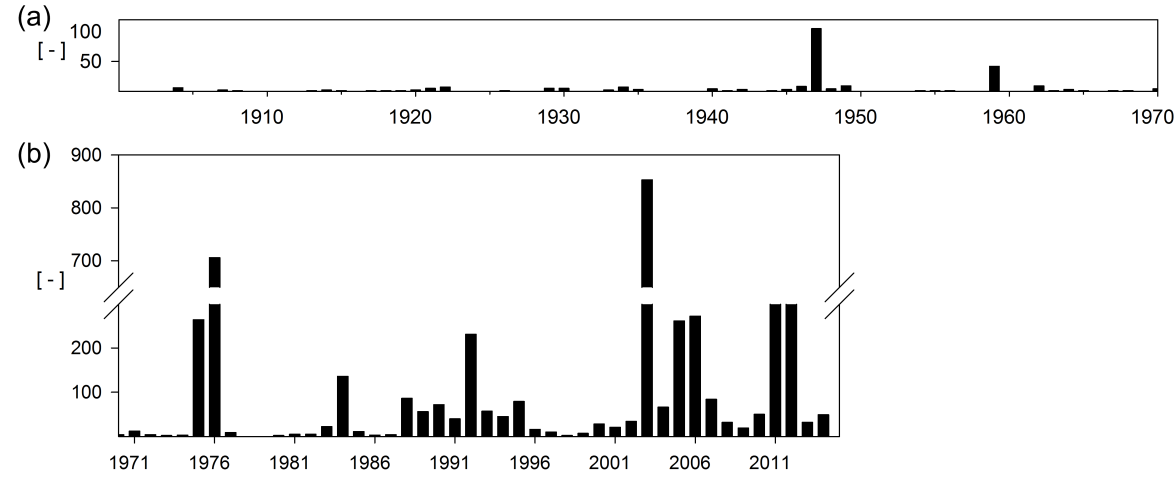

(c)
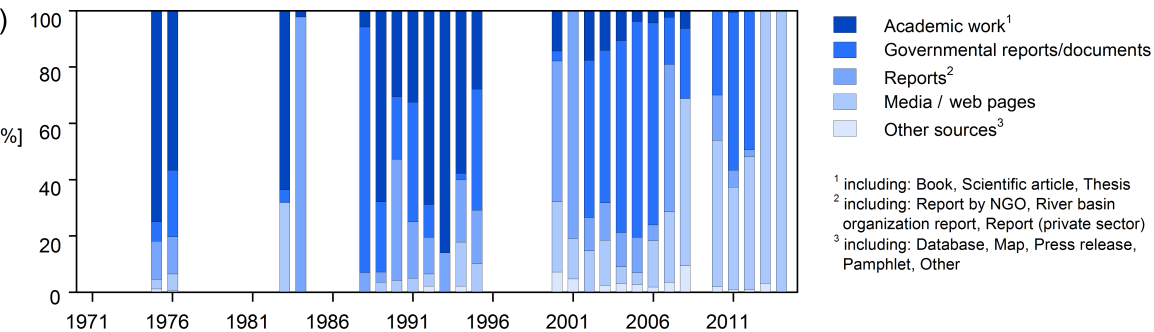

(d)
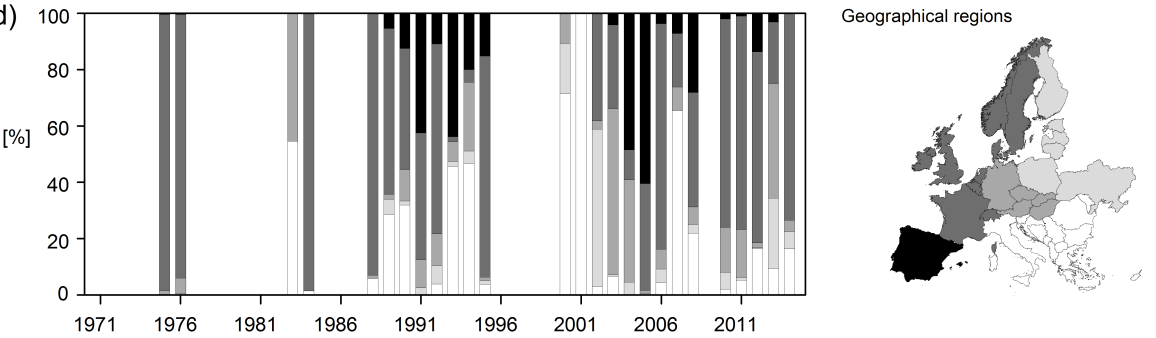

(e)
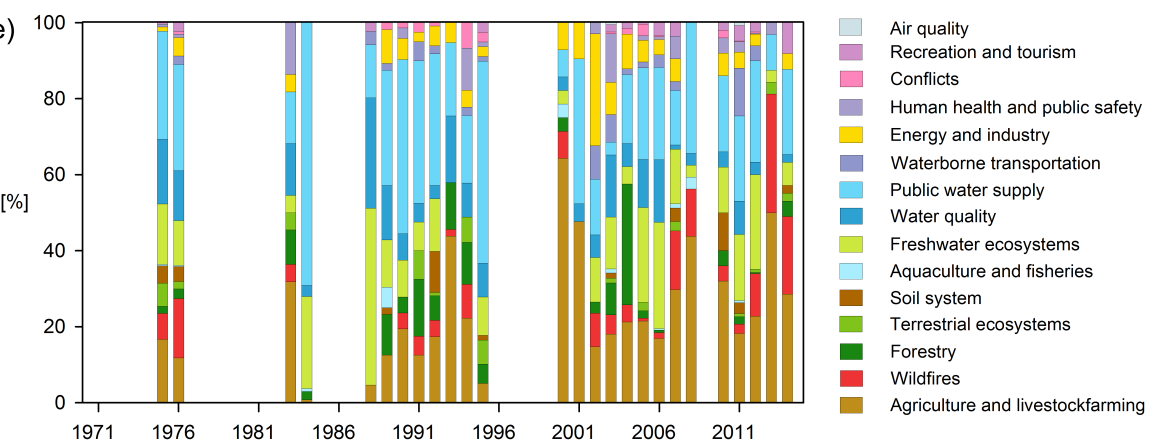

Figure 1. EDII contents over time: with (a) number of entries per year (according to the recorded impact start year) in the period 1900-70 and (b) from 1970 onwards. For years with $\geq 20$ reported impacts: yearly distribution of (c) report sources, (d) countries/geographical region, (e) impact categories.

\section{EDII database content}

\subsection{Impact data from 1900 to 2013 at a glance}

The EDII contains report entries since 1900 and Fig. 1 shows the annual time series of the content of the database (as of March 2015). Impact reports prior to 1970 correspond to well-known European drought years, such as the early 1920s, the second half of the 1940s, and 1959 (Fig. 1a). However, this earlier time period prior to 1970 is only sparsely covered by report entries in contrast with more recent times (Fig. 1b). Consequently, we focused our closer inspection of report sources and impact distributions on the period from 1970 to 2013, and specifically on years with at least 20 drought impact reports (Fig. 1b-e).

Within this 43-year study period, the largest numbers of reports refer to impacts reported in the year 2003, followed by 1975-76, 2011-12, and 2005-06 (Fig. 1b). Besides those events, the number of annual reports generally appears to have increased since the 1990s. The bulk of drought im- 
pact reports from the last 15 years (2000-2015) are reports published by governmental authorities or other institutions, whereas a considerable fraction of the earlier drought impact reports are based also on academic work (Fig. 1c). The fraction of media and internet sources becomes larger in more recent years, with the most current entries almost entirely based on these sources.

The collected impact reports cover many European countries and regions (Fig. 1d). Impacts in specific geographical regions, which we grouped based on simplified agroclimatic zones proposed by Bouma (2005), reflect the occurrence of regional drought events: for instance, reports in 2001 are mostly from southeastern European countries, in 2005 mostly from Spain and Portugal, and in 1976 mostly from maritime/western European countries (Fig. 1d). By contrast, the period from 1989 to 1995 is characterized by impact reports across several regions in Europe with reports in maritime/western Europe dominating the early years of this period and a high number of drought impact reports from Portugal and Spain as well as from southeastern European countries in the early 1990s (Fig. 1d). The fraction of impact reports from Northeastern European countries is relatively small.

The yearly distributions of reported impact categories (Fig. 1e) illustrate the characteristic diversity of drought impacts. Throughout, a substantial fraction of the reported drought impacts were assigned to the category "agriculture and livestock farming", "public water supply", and other impact categories directly linked to water resources. Impacts on "energy and industry" appear prominently during the early 2000s and reports on "freshwater ecosystems" comprise a large fraction since 2003. Reports in the category "terrestrial ecosystems" or those addressing social consequences, i.e., the categories "conflicts" and "human health", were only found for few years and are limited in number. Overall, recent years show a slightly more diverse and balanced distribution of the reported categories.

The annual distribution of impact categories and regions (Fig. 1d and e) reveals some agreement between a large proportion of reports from southeastern Europe, i.e., drought centered on this region, and increases in reports on "agriculture and livestock farming" (i.e., 1983, 1994, 2000-01). By contrast, large proportions of reports from western European countries generally coincide with a lower fraction of agricultural impacts (i.e., 1975, 1984, 1995, 2010) and more varied impact categories. In years with few impact reports, particular sources, regions, and impact categories often dominated the reported impacts in contrast to the wide range of reported impacts in other years.

\subsection{Geographical distribution of report sources and impact categories}

To date, drought impact reports in the EDII cover 33 countries, but there is a strong imbalance in the distribution of

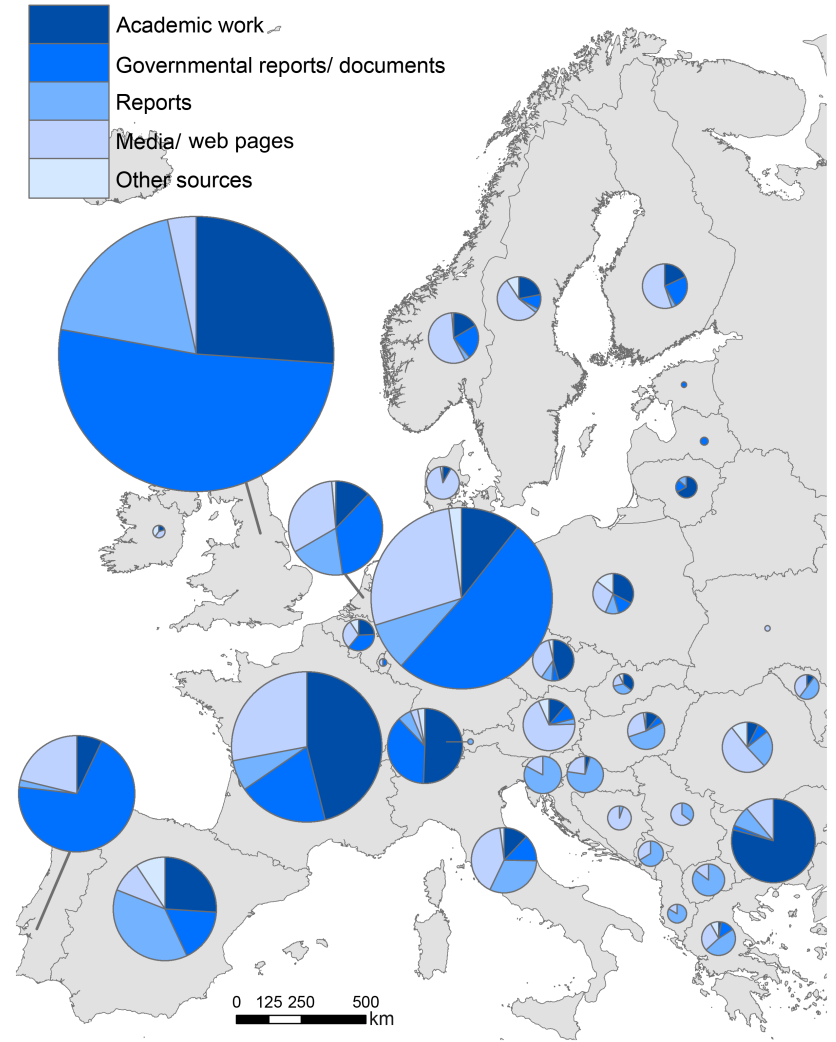

Figure 2. EDII contents by country, with the number of drought impact reports (pie size) and the distribution of underlying information sources (legend details as Fig. 1c).

entered reports per country (Fig. 2). This geographical imbalance is explained by a number of restrictions and biases regarding the availability of information to populate this database and Sect. 5 provides a more detailed discussion of the resulting limitations. The map in Fig. 2 illustrates some important differences regarding the composition of information sources within the current EDII. The UK, Germany, France, Portugal, the Netherlands, Spain, Bulgaria, Switzerland, Italy, and Norway are the 10 countries with the largest numbers of impact report entries (in order of decreasing numbers). Most of these countries are located in western Europe. Bulgaria is the only country located in eastern Europe. For Bulgaria, a particular academic information source (Knight et al., 2004), which had previously compiled Bulgarian drought impact information over a long historical period was available. In countries with many reported drought impacts, often governmental reports comprise a high fraction of the EDII entries. Such reports are mostly systematic reviews of a past drought situation and thus provide all necessary information for the EDII (time, location, etc.). In countries with generally fewer impact reports, reports by nongovernmental sources as well as internet and (international) media sources comprise a higher fraction of the information sources of drought impact reports (Fig. 2). 


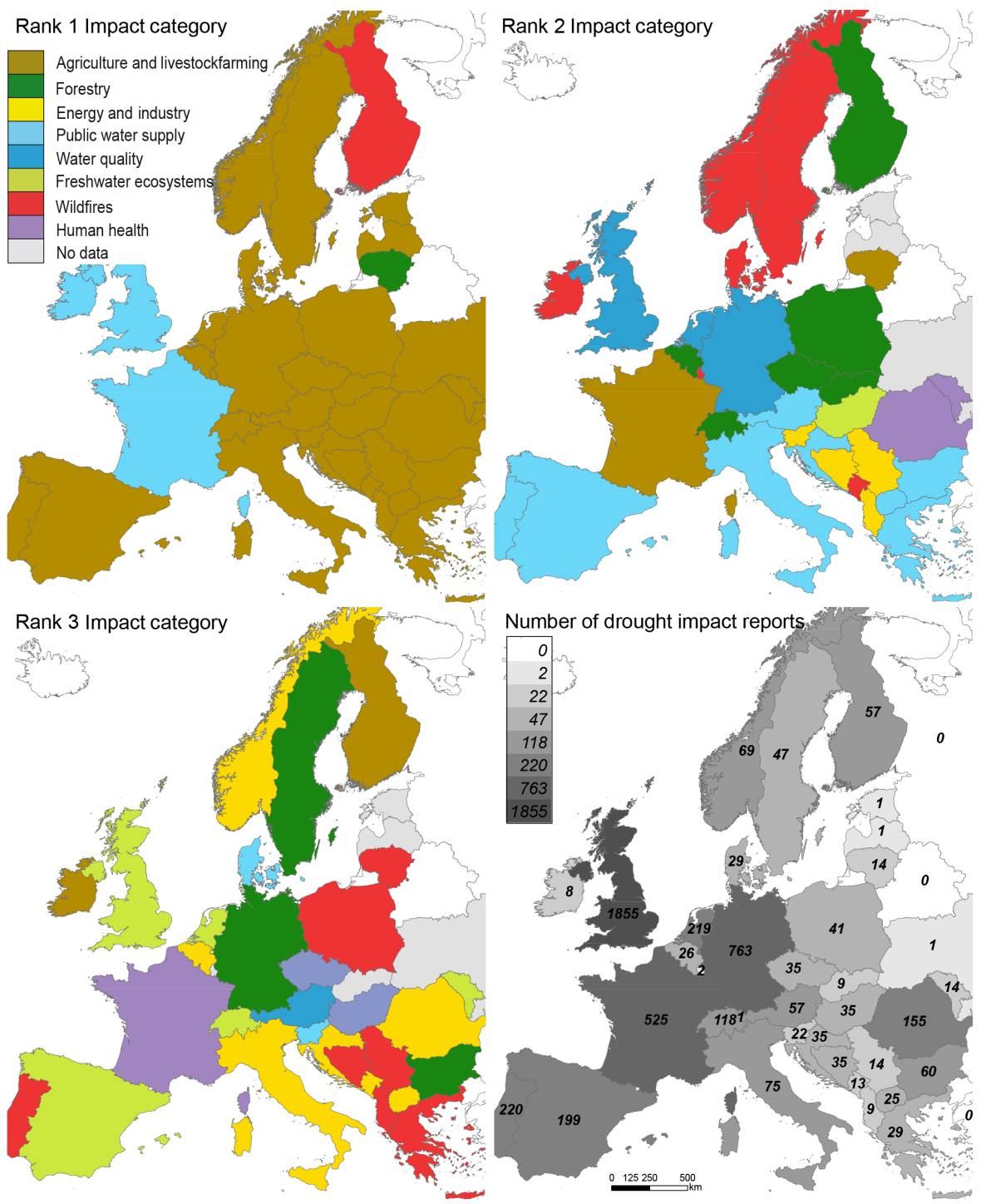

Figure 3. EDII contents by country: top three (most frequently reported) impact categories (Ranks 1-3) and the total number of drought impact reports in the database.

Figure 3 shows the relative ranking of the three most frequently reported impact categories for each country across Europe. The relative frequency within each country is independent of the absolute number of reports and hence less affected by quantitative report bias. The category "agriculture and livestock farming" ranks highest most often and ranks among the top three most frequently reported impact categories for all countries except Finland (Fig. 3). Only eight out of the 15 available EDII impact categories are represented in these top three impact categories. Besides agriculture, these are most often the impact categories "public water supply", "energy and industry", and "wildfires", followed by the categories "water quality", "freshwater ecosystems", and "human health and public safety". Categories that are nowhere represented among the three most frequent cat- egories are "freshwater aquaculture and fisheries", "waterborne transportation", "tourism and recreation", "terrestrial ecosystems", "soil systems", "air quality", and "conflicts".

The high fraction of impacts on "public water supply" in southern (Mediterranean) countries is in agreement with the common perception of susceptibility to quantitative water supply problems due to water scarcity in the region. The fraction of reports in the "forestry" category is greater in forest-rich countries in northern and eastern Europe. Impacts on "wildfires" also rank highly in these countries, although in absolute numbers, available EDII data are scarce. Impacts on energy and industry rank highly in Norway, Belgium, and several countries in southeastern Europe. Impacts on "water quality" rank highly, in terms of relative frequency, for the UK, the Netherlands, and Germany. "human health and 


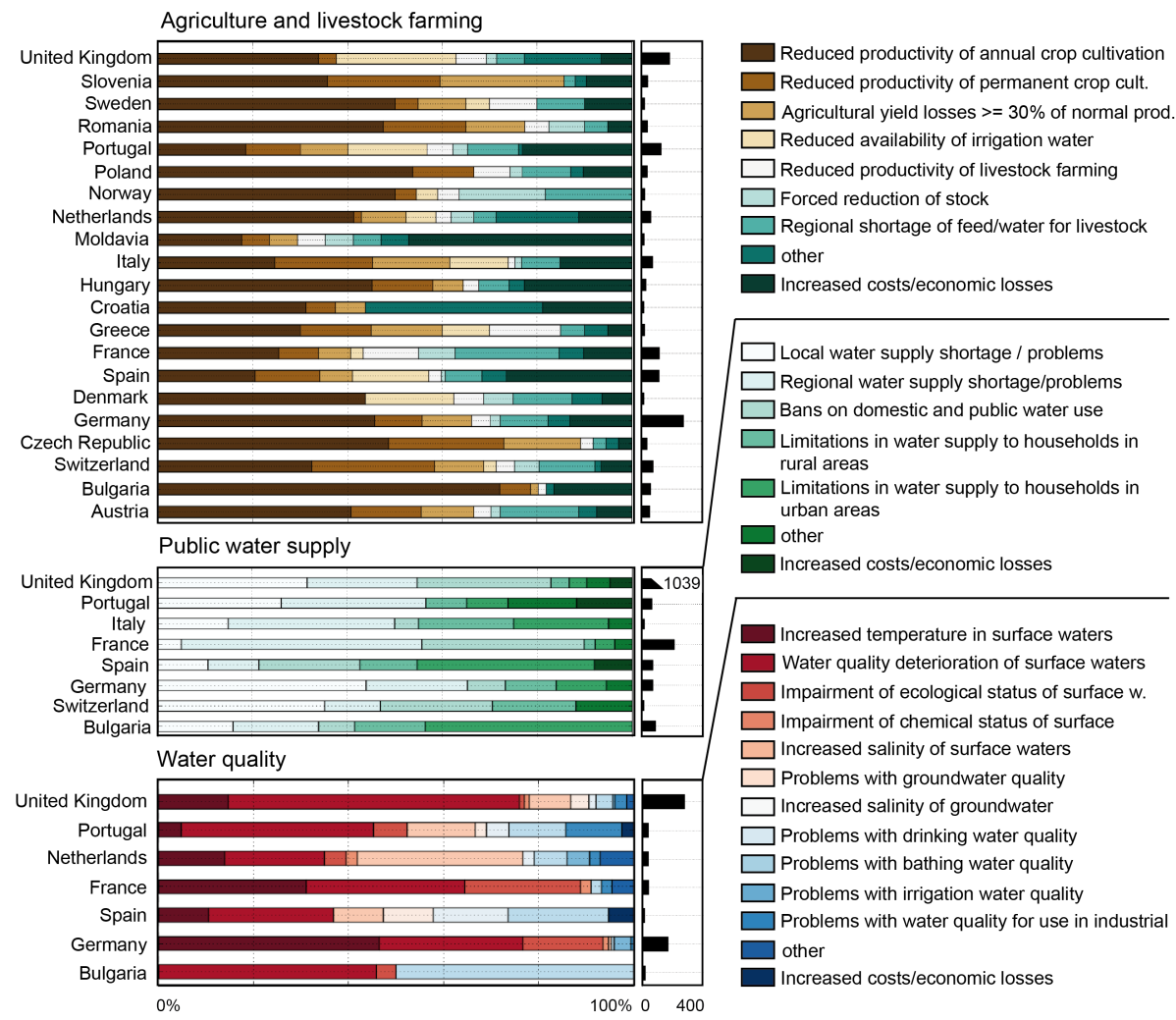

Figure 4. Reported impact types in three selected impact categories for countries with availability of $>15$ reported drought impacts in the specific category. Impact type descriptions in the legend are shortened from Table A2.

public safety" impacts were identified in five countries. Nevertheless, the latter category includes a wide range of impact type subcategories. An analysis of the impacts' text descriptions in the EDII revealed that, in the case of France, the high fraction of reported impacts results mainly from a multitude of reports of increased human mortality rates during the associated heat wave in 2003. However, for Moldova, the "human health and public safety" category ranks second with 2 out of a total number of only 14 drought impact reports. Here, the reports deal with food security issues in response to the droughts in 1946 and 2007. These examples demonstrate the diverse nature of reported impacts within one broad category.

\subsection{Reported impact type subcategories}

The EDII's two-level categorization scheme of assigning main impact categories and more detailed impact types within each category (see Table A2) facilitates a further differentiation of the differences of reported impacts across Europe. The category "agriculture and livestock farming" is separated into nine impact types. Their relative fractions were assessed for 21 countries with high data availability (Fig. 4, upper panels). The proportion of impact types were similarly assessed for the two impact categories "public water supply" and "water quality" across a selection of seven countries with high data availability in the EDII (Fig. 4, lower panels).

For "agriculture and livestock farming", reported impacts that relate to a reduced agricultural production and to crop yield losses comprise the largest fraction of the overall agricultural reported impacts. A considerable fraction of reported impacts also relates to livestock farming, particularly in France, Hungary, and Moldova. The reported impact types also demonstrate the importance of irrigation in some regions through a high fraction of impact types related to irrigation (e.g., "Reduced availability of irrigation water") in the Mediterranean countries (Spain, Greece, Italy, and Portugal). Compared to other impact categories, the impact type describing economic losses was more often reported in the "agriculture and livestock farming" category, even though losses were rarely quantified.

For the category "public water supply", the distribution of impact types shows some differences among countries. Within this category, the different impact types categorize increasing impact severity ranging from a mere reporting of shortages to imposed restrictions (e.g., for outdoor water use such as gardening or pools) to actual limitations in the public water supply (e.g., water supply could no longer be provided). In general, the majority of reports describe local or regional water shortages and thus primarily aim to raise 
awareness. France and the UK have a high total number of reported water supply impacts, with a relatively high fraction of use bans aiming to reduce demand and conserve water. Bulgaria, Spain and Italy have the largest fractions of reports on actual supply limitations during droughts. Reports on increased costs for the public water supply sector were only available for Portugal, Spain, and the UK.

Within the category "water quality", impact types are classified by their relevance to particular water quality aspects such as temperature, the impaired water service (ecological status, drinking water, irrigation water, etc.), and general consequences. The type "water quality deterioration in surface waters" typically constitutes a substantial fraction of impact types in all countries, whereas other impact types appear to be more specific to certain countries. In Germany and France, a significant fraction of the reports relates to increased surface water temperature, as the majority of reported water quality impacts refer to the severe summer droughts of 1975-76 and 2003 that were associated with very hot weather conditions. High surface-water temperatures during these droughts heavily impacted the energy sector due to an impaired water use for cooling of thermal power plants (fossil and nuclear). In Germany, bathing water quality impairments affected recreational activities during the summer holiday time, but drinking water was rarely impaired. In the Netherlands, a comparatively large fraction of reported impacts in the "water quality" category deal with increased salinity of surface waters as a result of direct saltwater intrusion in the river mouths and a higher proportion of brackish groundwater infiltration into the rivers. Increased salinity (of surface water or groundwater) also appears to be a threat for Portugal, Spain, and the UK. Water quality problems with drinking water comprise considerable fractions of reports in Portugal, Spain, and particularly in Bulgaria.

\section{Impacts of selected large-scale European drought events}

We extracted subsets of the current EDII contents for selected historical drought events and specifically assessed them on an event basis. The events were chosen to cover different regions and impact distributions at the expense of some more well-known regional droughts, such as the 1991-95 on the Iberian Peninsula. Besides looking at the reported impact data frequencies in time and space as in the previous sections, we also analyzed the impacts' text descriptions. As a summary, the occurrence of certain words in these text descriptions is presented in the form of word clouds with the words scaled to the frequency of their use in the text descriptions (Fig. 5). Similar information from other events can be found in the detailed event-based summaries in the European Drought Reference Database (EDR, see Stagge et al. (2013); http://www.geo.uio.no/edc/droughtdb/edr/DroughtEvents/).
For better comparison of events of similar spatial extents, the events were organized into:

a. large-scale drought events, chronologically consisting of the three droughts of 1975-76, 2003, and 2011-12 that covered large areas across Europe (Fig. 5, upper row left to right panels);

b. regional drought events covering slightly smaller areas, chronologically including the four events of 1989-90 in France and the Mediterranean, 1992-94 in northern, central and eastern Europe, 2004-08 on the Iberian Peninsula, and 2006-07 in southeastern Europe (Fig. 5, lower row left to right panels).

The drought of 1975-76 was a benchmark drought in Europe among the large-scale events. The majority of impacts were reported in 1976 in central Europe, although impacts were already reported in the UK, Denmark, and Northern Germany throughout the year 1975. Agriculture and livestock farming suffered over the entire affected region (Fig. 5, upper panels), particularly during the summer of 1976. Besides agricultural losses, impacts were also noticeable for households through increased prices for vegetables and dairy products as well as through losses in kitchen gardens. Water supply shortages were mainly reported in the UK and France, and were largely limited to rural areas. Rivers across Europe recorded low flows and deteriorated water quality, affecting navigation, energy and industrial production and aquatic and terrestrial ecosystems.

The drought of 2003 was a shorter, but more widespread and intense event with impacts in southern, eastern, and central Europe (Fig. 5, upper panels). At the peak of the event, impact reports reflect effects of water shortages combined with high temperatures. The fraction of impacts on public health, on recreation and tourism, as well as the temperature-related energy sector, was higher than during the event of 1975-76, possibly a consequence of the water shortages and higher temperatures. Agricultural losses were again widespread. Water supply problems were reported mostly from small local water suppliers in the Alps and other mountain areas. However, compared to 1975-76, 2003 reports show a smaller fraction of water supply impacts and a larger fraction of water quality impacts, which were often related to the high stream water temperatures. As a result, impacts on freshwater ecosystems were frequently reported in 2003, as were impacts on energy and industry. These categories are reflected in the frequently used words "fish", "power production", and others. As well as the record number of forest fires, the 2003 drought appears to have caused large damage to forests, which showed lagged impacts in subsequent years (e.g., through dieback and pest infestations).

The most recent large-scale drought of 2011-12 differs from the other two large-scale events. It had a wider spread of impacts in space and time and a slightly different impact distribution with a lower fraction of impacts related to pub- 

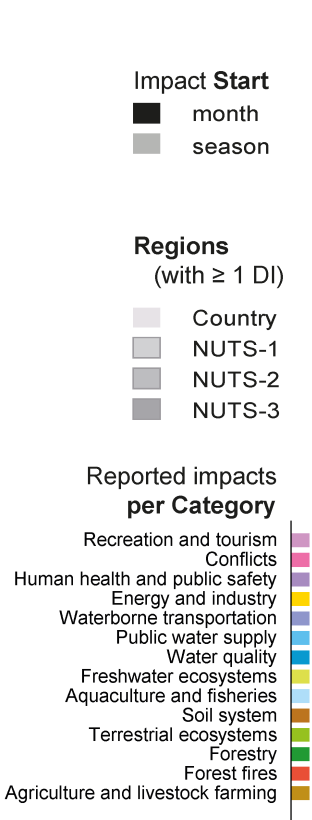

Most Frequent Words in Text Descriptions* in alphabetical order, size $\sim$ frequency

* excluding: water, drought, dry, weather, year, affected, caused, led, result, effect, impact, consequence, observed, estimated, reported
study, several, due, according, and common English words (e.g. and etc.)

1989-90 Mediterranean

\begin{tabular}{l|l|l|l|l}
$\%$ & 1989 & 1990 & 1991
\end{tabular}

15

10

$5 . \quad$ II Ine nIIII I Dec Jun Dec Jun Dec Jun
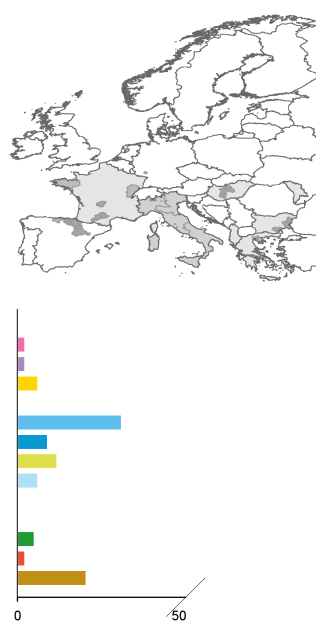

agricultural $\mathrm{a}$ rea $\mathrm{S}_{\text {вugas case crop dam domestic }}$ drying farmers fish Hepatitis hours inceresed

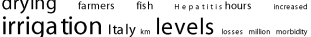
xxyen-concentracosos perioses production reacheser reduced

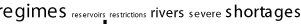
coum s upply towns nom
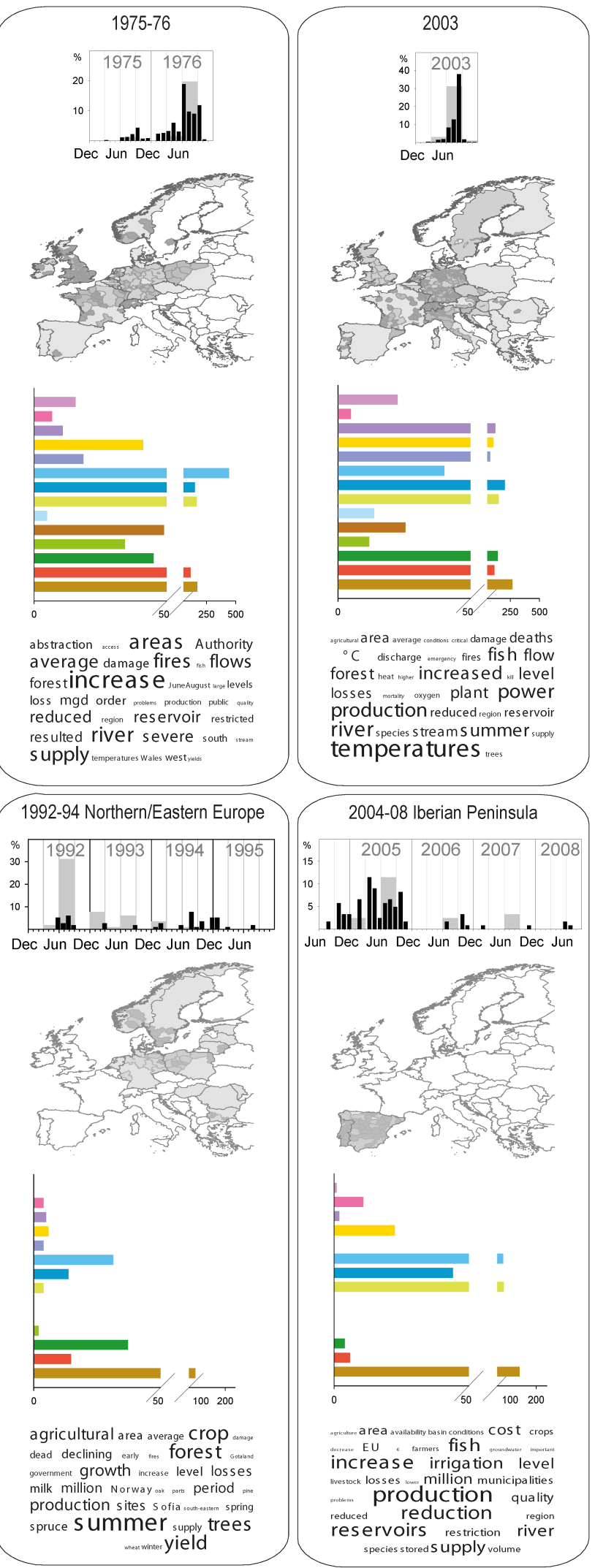

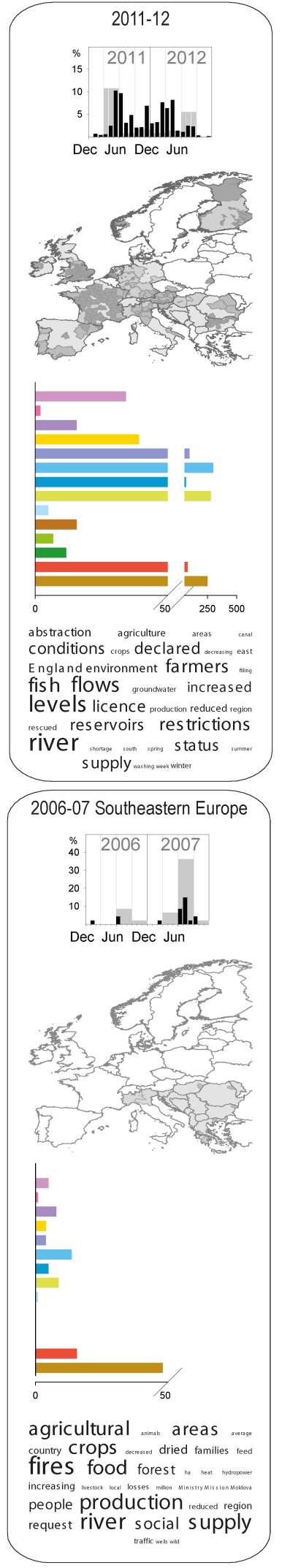

Figure 5. Reported drought impacts for selected European drought events during the period 1970-2013. For each event, the following characteristics are shown (up to down panels): temporal distribution of reported impact starts, geographical location of reported impacts, number of impacts per category, and most frequent words in text descriptions (word clouds generated with TagCrowd.com). 
lic health, terrestrial ecosystems, and forests. In contrast to 2003, impacts were not constrained to the summer season but occurred over a long time period and a large fraction of the reported impacts were reported in the UK. The word "England" is one of the frequently used words in the text descriptions, as are words that relate to water use restrictions. The number of reported impacts on waterborne transportation, however, is as high as in 2003, as major European navigation routes such as the rivers Rhine and Danube, were affected by extreme low flows. Similar to the 1976 drought, a high number of impacts on water supply and freshwater ecosystems was reported. The dominance of these impact categories is reflected in "levels" and "river" being the most frequently used words in the text descriptions.

A number of smaller-scale regional drought events occurred in Europe. Based on the impact reports in the EDII, we distinguished events with different impact distributions. The 1989-91 event in the eastern Mediterranean (Fig. 5, lower panels) was dominated by impacts on water supply, e.g., in Greece, Sicily/southern Italy. However, impacts were also reported in France and Spain. The regional event of 1992-95 in northern and eastern Europe (Fig. 5, lower panels), is unique with an unusually high fraction of reported impacts on forestry in the Northeast and water supply in the southeast. The event of 2004-08 on the Iberian Peninsula is characterized by many reported impacts on agriculture, water supply, water quality and freshwater ecosystems. During this long-term drought, the number of reported impacts in the category "conflicts" was higher than for any other event (Fig. 5, lower panels). The most recent event of those selected, i.e., that of 2006-07 in southeastern Europe peaked with the emergence of an unprecedented heat wave in June 2007 and many forest fires. During this event, in Moldova, food security was threatened due to severe impacts on agriculture.

Overall, Fig. 5 shows that drought impacts have been reported in all seasons, especially for the regional multi-year events, e.g., 1992-94 and 2004-08. However, as impacts tend to be more frequent during the summer seasons, the word "summer" was found to be a frequently used word in the text descriptions. The impact descriptions of the large-scale events of 1975-76 and 2003 also contain numerous references to "temperature" as they were accompanied by heat waves in western and central Europe. In contrast, the word "winter" appears only in the word cloud for the event of 2011-12. Impacts on agriculture, water supply, and water quality dominate for most drought events, and the respective words, such as "agricultural", "area", "crops", "supply" are therefore used frequently in the text descriptions. During three large-scale events, 1975-76, 2003, and 2011-12, a wider range of impacts was generally reported than for the regional events. Whereas impacts on agriculture and water supply dominate all large-scale and regional events, the regional events show specific differences in distribution of the other impact categories that possibly relate to the typical regional water use, economic sectors and relevance in the respective region. For instance, the reports for events that specifically affected the Mediterranean (e.g., 1990, 2004-08, 2006-07) often mention the words "irrigation", "restriction", "shortage", "cost", "request" and "urban", which suggest a high degree of societal impact. Reports for the event of 1992-1994, which was characterized by a high number of impacts on northern forests, on the other hand, frequently use the words "forest" and "spruce".

\section{Discussion}

\subsection{Challenges in collecting and organizing drought impacts}

The EDII database was developed and populated as part of a 3-year research project (Stahl et al., 2012; Van Lanen et al., 2015). The EDII's classification scheme of impact categories and subordinate impact types (Table A2) was modeled after the US Drought Impact Reporter (DIR), but was adapted to the project's needs and thus has a more detailed classification scheme. The process of describing, assigning an impact to a category and associated subtype, and entering time and space information may present some challenges if it is to be part of a real-time monitoring tool such as the DIR, but for a research database, it has the advantage of allowing an unprecedented detailed stratification and assessment of the gathered data. So far, the scheme has proven to be suitable for capturing impact details and all impacts found in the collected reports could be categorized. It should be kept in mind that the EDII is limited to only considering and categorizing negative impacts of drought. Drought can also have positive impacts. For instance, in the agricultural sector, there may be winners and losers during the same drought (e.g., Ding et al., 2011, Musolino et al., 2015). Furthermore, text descriptions in the EDII were not standardized; the only requirement is that the text descriptions are in English and reflect the text of the original information source as closely as possible. Although the text descriptions often contain common terminology, differences in translation or synonyms may have introduced uncertainty. We identified the correct categorization of reported impacts as the critical step to enable an objective comparative assessment and concluded that a moderator who performs a screening and quality assessment of the data is crucial before impact reports are accepted into the database.

Governmental reports and documents make up a high fraction of referenced sources in the EDII (Fig. 2). Governmental reports by national or regional authorities involved in the monitoring and management of droughts were found to provide rather detailed information on the occurrence of past drought impacts, and thus proved to be particularly useful for the historical reconstruction of drought impact distributions. It was crucial that a clear association between drought impact and event was given in the referenced source. Lack- 
strom et al. (2013) named this clear association as one of the major difficulties in drought impact reporting owing to the complexity of drought impacts, especially the complexity of multiple stressors and temporal indefinability of drought. Governmental reports are usually edited in the respective national language. In addition, governmental reporting culture varies across Europe and hence the availability of such reports also differs. By contrast, academic output and reports by multinational organizations are available in English, but are often less detailed on the nature of the impacts. These academic articles and reports represent the major information sources of reported drought impacts in the EDII for countries in eastern Europe to date (Fig. 2).

During the limited time available within the 3-year project, the search for drought impact reports revealed a wealth of information on a variety of drought impacts across most of Europe, even though it was carried out by a group of people limited to searching in only a few European languages, particularly lacking Slavic languages. Generally, the requirement for and availability of data has increased with the emerging prevalence of digital documents and online dissemination techniques during the 20th century. This is reflected in the contents of the database (Fig. 1). There are more reports and categorized impacts for more recent droughts. In our assessment, this limits a quantitative comparison of the larger samples of impacts for the more recent drought events, e.g., 2003 and 2011-12 to those of earlier events (Fig. 5). That the number of drought impacts may be more strongly related to the availability of reports than to the severity of drought impacts confirms the relative approaches taken in this study.

Similarly, the identification of the time and location of reported drought impacts challenges the resolution and accuracy of the data set. The specific month in which an impact started and ended was often not detailed in the original information source and as a consequence, many database entries only state a season or even only the year of occurrence. For instance, for the selected drought events assessed in Sect. 4, between 15 and $41 \%$ of the reported impacts did not specify the month or season of impact start (Fig. 5, top graphs). However, during a severe drought, similar impacts tend to be reported by many sources, and we assume that seasonal information still provides a valuable estimate of the onset of major impacts. The same issue applies to the end of an impact. Similar to difficulties to define the termination of drought as a natural phenomenon (Parry et al., 2015), the termination or recovery of drought impacts remains largely unknown, as recovery is rarely reported, which is an issue not yet widely addressed (Lackstrom et al., 2013). Introducing links between entries would allow the identification and tracking of multiple reports of the same impact - this would enable an accurate timeline of impact onset and end to be created. Currently, this information must be distilled manually from the database.

The spatial reference (and so the reported NUTS levels) also shows high variability in the level of information details provided. Often, the original source provides only vague location information; then, a larger spatial unit within which the reported impact occurred had to be selected for the categorization. Consequently, for some regions and events, especially those with sparser data coverage, reported impacts rarely referred to subnational scales (e.g., drought events in 1990 and 2007 in Fig. 5), whereas for other regions, more detailed spatial information was available (e.g., drought events 2004-08 in the Iberian Peninsula and generally in Germany). Occasionally, however, reports were very specific. For instance, in some cases energy production impacts were provided for specific hydropower sites or fish kills for particular sections of rivers. The flexibility to aggregate from lower (local) to higher (regional/national) levels is desirable but known to be challenging (Lackstrom et al., 2013).

The information gathered provides a number of opportunities for further assessment, provided the limitation and biases inherited in the collection of impact reports are kept in mind. One opportunity not yet explored, due to the low number of entries, is an investigation of associated secondary impacts and response measures that relate directly to reported impacts. A retrospective analysis for the few entries that are available, however, could be a starting point to trace the success or failure of these measures by cross-referencing with other documentation and information sources. Such an analysis has potential to help improve drought management. Another option is to investigate the link between monitored drought indices and the occurrence of drought impacts as demonstrated in several recent studies (e.g., Bachmair et al., 2015; Stagge et al., 2015). Such analyses may guide the choice of impact related indicators for risk assessment and drought monitoring and early warning. Given the current status of the EDII, the most reliable report samples for panEuropean assessments are aggregated information on an annual scale and at the country scale or larger European regions. This is the resolution used by Blauhut et al. (2015a) to model annual likelihood of impact occurrence by the standardized precipitation and evapotranspiration index; and by Van Loon et al. (2015) to study the impacts of temperaturerelated drought types. However, the more detailed the spatial and temporal reference, the more details can be gained in the identification of similarities and differences across Europe. Bachmair et al. (2015) compared the statistical link between drought impacts and a number of different hydrometeorological drought indicators across Germany based on a higher spatial resolution (NUTS-1 regions); Stagge et al. (2015) used the available monthly impact occurrence for selected countries to identify the best hydrometeorological drought predictors of the likelihood of impact occurrence and addressed the database's biases by building trends into the model. All studies conclude that in order to derive a useful sector-specific operational drought index, future efforts to compile drought impact data should aim at using available higher resolution in time and space that is closer to the resolution of hydrometeorological drought indices. 


\subsection{Emerging patterns in reported drought impacts}

Impact reports show a wide range of impacts locally and across Europe. Additionally, impact categories and types appear to have increased in diversity over time (e.g., Fig. 1). Whereas such patterns may be related to the overall increase of information availability over time, it may also reflect an increased public awareness (e.g., Wilhite, 2007; Dessai and Sims, 2010), or specific changes in the importance of the impact-related economic sector, both in governance or policies (De Stefano et al., 2012; Tánago et al., 2015; Blauhut et al., 2015b). The spatial distribution of the sheer number of reported impacts in the EDII differs to those recorded in other databases. For example the Emergency Events Database (EM-DAT, http://www.emdat.be) from the Université Catholique de Louvain in Brussels in Belgium generally returns few entries for Europe compared to other continents, but these are mainly from Mediterranean and (south)eastern European countries. However, with a focus on disasters, EM-DAT and other databases use other definitions for drought impacts.

Availability and accessibility of impact information from reports appears to vary across Europe and thus introduces bias in the volume of information on impacts. In some countries, regular reports detailing the status of a water-dependent sector or special reports detailing a particular drought event were rich sources that provided many database entries. Examples of the former type of regular reports that were used include the drought monitoring briefs for England and Wales produced by the Environment Agency for the 2004-6 and 2010-12 droughts in the UK. Such reports also highlight a sectoral relevance that differs regionally. Comprehensive reports or books on specific drought events for example covered the drought of 2003 in Germany and Switzerland, the event of 1992-94 in Bulgaria, and the event of 1975-76 in the UK. In other regions, such previously assembled information sources were not available and assembling impact information was more tedious and resulted in fewer database entries. In addition, the EDII still lacks targeted searches for information in several countries and languages. For example, data entries for many eastern European countries rely mostly on international report sources and media coverage available online. As a result of these regional differences, the volume of EDII contents is biased, and therefore our analyses focused instead on the relative fractions and composition of impact reports within each region.

Agricultural drought impacts represent the largest fraction of impacts in most regions across Europe (Fig. 3) and for most large-scale or regional drought events (Fig. 5). This explains why research on drought impacts across Europe has often used crop failures, losses or yields and other types of drought impacts have been considered less often. Consistent with the conceptual view of drought propagation from its origin as a precipitation deficit to a deficit in soil moisture and finally to hydrological deficits (in groundwater and streamflow, and related water resources), the dominance of agricultural reports may also reflect the typical association the public has with drought. In addition, where agriculture is irrigated, agriculture is often the major water user. This reliance on water for agriculture may explain the high visibility and awareness (Ding et al., 2011) and thus the increased report availability of agricultural impacts. The impact category "agriculture and livestock farming" also records the most entries for cost and losses, suggesting a high economic visibility in Europe (Fig. 4). The relevance is also reflected in the efforts of drought monitoring systems targeting agricultural drought, e.g., the European Drought Observatory (Sepulcre et al., 2012) or the Drought Managment Centre for Southeastern Europe (e.g., Ceglar et al., 2012).

Public water supply impacts have also been reported frequently. If considered together with impacts on water quality and freshwater ecosystems, they comprise an even larger fraction of impacts that relate to direct impacts on water resources than impacts on agriculture. In the Mediterranean countries, the fraction of reported impacts on public water supplies is particularly large. These numbers confirm general public perception of drought importance on public water supply impacts in the south. This was illustrated, for example, by stakeholders mapping drought impacts during the 2nd DROUGHT-R\&SPI pan-European Dialogue Forum, where water supply was consistently labeled as a concern by Mediterranean stakeholders (Stahl et al., 2014, 2015). In addition, the details of reported impact types in this category revealed that water supply impacts in southern regions were more severe. They have been affected by actual limitations to households and drinking water supply, whereas other regions in Europe only reported preventive water use bans to decrease demand (Fig. 4). Future work could investigate the feasibility of assigning a relative severity to impact details to improve the ranking and analysis of such differences.

Our analyses show that that physical drought characteristics may be linked to the impact characteristics (Fig. 5). Summer droughts combined with heat waves, for example, have invoked unusual impacts on public health and on energy and industry by restricting river water use for cooling. Multi-year events in southern Europe (e.g., Estrela et al., 2000) and in the UK (e.g., Folland et al., 2015) have specifically reduced storage levels (surface reservoirs and groundwater), provoking conflicts among users. The factors controlling meteorological, hydrological, and soil moisture drought in Europe have been previously analyzed (Hannaford et al., 2011; Lloyd-Hughes, 2012; Van Loon and Van Lanen, 2012; Tallaksen and Stahl, 2014). The EDII provides a potential data source to investigate the importance of drought severity, surface characteristics, and water management in producing drought impacts. This data set, or similar products, may provide the necessary link to evaluate whether drought metrics can predict impacts, a research goal consistently stated (e.g., Kallis, 2008). 


\section{Conclusions}

The EDII, a novel European database of reported drought impacts, was established to facilitate the use of textual evidence and categorized information on drought impacts at the pan-European scale for a variety of analyses. The collaborative development of the database and its protocol for impact classification by an international group of researchers provided novel insight into the nature of drought impacts across Europe. The collected and analyzed impact report data constitutes the first comparative view of drought impacts across Europe's different geo-climatic regions and a unique basis for studies relating physical characteristics of the natural hazard of drought events to their various impacts. This contributes to the filling an information gap on drought impacts and provides a useful data source for studies linking the hydrological characteristics of droughts with their effects on society at large. Already in its present state, the EDII database confirms the large variety of impacts associated with drought hazards and suggests differences and commonalities among regions and events.

As some examples illustrate, the insights from the impacts' text descriptions will be critical for drought management and policy development and call for more in-depth studies. An important finding was that impacts are diverse in Europe, suggesting that drought management and policy cannot only target one specific sector. The findings further call for a monitoring of variables besides precipitation, e.g., soil moisture, groundwater, and reservoir levels, possibly return flows and reusable wastewater where applicable, and water quality indicators including water temperature, for improved impact-specific drought indicators. Over time, the diversity of impacts appears to have increased, and impact details may have changed in response to a more complex society and infrastructure, as has the awareness of the drought hazard, emphasizing the need to increase adaptive capacity. Although impact distributions appear somewhat similar across Europe, the implications and severity of a given event may vary. These details need to be further elucidated, which requires accurate and comparable, more quantitative reporting. Apart from the agricultural sector, little information is available on the economic cost of drought impacts is available. Access to such information likely requires accessing other information sources.
An assessment of the representativeness of the database with respect to European drought impacts and their severity will be a key to any future, more detailed, study. Along with updating and populating the database, continuous efforts are needed to improve the quality of its content and to develop novel approaches to account for the aforementioned uncertainties in categorizing the impact reports, as well as limitations in the data samples at specific spatial and temporal scales. Any specific analysis will need to select, complement, and process the impact data to create suitable samples. It is recommended that further work evaluate the use of more advanced methods to incorporate the textual information than the word frequency ranking presented here. It is anticipated that the combination of different data sets and the use of inter- and trans-disciplinary approaches in drought impact assessments is a promising way forward that will increase the confidence and usefulness of the EDII database.

Despite some biases in its current content, the EDII database constitutes a valuable resource that provides insights into the characteristics and regional patterns of drought impacts. There are still limitations and challenges ahead, but the presented material demonstrates the benefit and potential of such a database of drought impact information at the pan-European scale. European researchers have significant information and expertise regarding droughts; however, this expertise is distributed across many countries and often is not compiled. The EDII is designed to consolidate this drought knowledge. Access to this online database hopefully will inspire public participation. It is our hope that this website will become a standard reference tool and grow with time as more users participate in data collection, sharing, and analysis. 


\section{Appendix A: EDII database categories}

Table A1. Overview of information sources for drought impacts entered into the EDII (Stahl et al., 2012).

\begin{tabular}{ll}
\hline Type of source (selection) & Explanation/examples \\
\hline Journal article & Article in scientific or professional journals \\
Book & Book, edited volume or book chapter/section \\
Newspaper article & Article in any newspaper or magazine in the popular press \\
Government report & Reports by national and regional water/environment agencies etc. \\
(Other) government document & Other government issued sources \\
River basin organization report & Reports by river basin organizations \\
Report by NGO (non-governmental organization) & Reports by environmental, social justice, and other organizations \\
Report by private sector & Report, e.g., by insurance company, water/energy industry \\
Press release & Press releases by stakeholders or agencies \\
Thesis & Academic work \\
Pamphlet & For example, information note by water supply company, city, etc. \\
Personal Observation & Personal observation by contributor or contact (e.g., from interview/stakeholder workshops) \\
URL (web page) & Internet resources not published in official reports \\
Map & Maps \\
Other & Any other information source \\
\hline
\end{tabular}


Table A2. EDII Impact categories and type subcategories (modified from Stahl et al., 2012).

\begin{tabular}{|c|c|c|}
\hline Impact category & $\operatorname{Imp}$ & ct type \\
\hline \multirow[t]{9}{*}{$\begin{array}{l}\text { Agriculture and } \\
\text { livestock farming }\end{array}$} & 1.1 & $\begin{array}{l}\text { Reduced productivity of annual crop cultivation: crop losses, damage to crop quality } \\
\text { or crop failure due to dieback, premature ripening, drought-induced pest infestations } \\
\text { or diseases etc. }\end{array}$ \\
\hline & 1.2 & Reduced productivity of permanent crop cultivation \\
\hline & 1.3 & Agricultural yield losses $>=30 \%$ of normal production (EU compensation threshold) \\
\hline & 1.4 & Reduced availability of irrigation water \\
\hline & 1.5 & $\begin{array}{l}\text { Reduced productivity of livestock farming (e.g., reduced yields or quality of milk, } \\
\text { reduced stock weights) }\end{array}$ \\
\hline & 1.6 & Forced reduction of stock(early selling/slaughtering) \\
\hline & 1.7 & Regional shortage of feed/water for livestock \\
\hline & 1.8 & Other \\
\hline & 1.9 & Increased costs/economic losses \\
\hline \multirow[t]{9}{*}{ Forestry } & 2.1 & Reduced tree growth and vitality \\
\hline & 2.2 & Decrease in annual non-timber products from forest trees (e.g., cork, pine nuts, etc.) \\
\hline & 2.3 & $\begin{array}{l}\text { Increased occurrence of water stress indicators and damage symptoms (e.g., } \\
\text { premature ripening, seasoning checks, defoliation, worsened crown conditions etc.) }\end{array}$ \\
\hline & 2.4 & Increase of pest/disease attacks on trees \\
\hline & 2.5 & Increased dieback of trees \\
\hline & 2.6 & Increased dieback of planted tree seedlings (in nurseries or afforested area) \\
\hline & 2.7 & Damage to short rotation forestry plantations (energy forestry) \\
\hline & 2.8 & Other \\
\hline & 2.9 & Increased costs/economic losses \\
\hline \multirow{4}{*}{$\begin{array}{l}\text { Freshwater } \\
\text { aquaculture } \\
\text { and fisheries }\end{array}$} & 3.1 & Reduced (freshwater) fishery production \\
\hline & 3.2 & Reduced aquaculture production \\
\hline & 3.3 & Other \\
\hline & 3.4 & Increased costs/economic losses \\
\hline \multirow{5}{*}{$\begin{array}{l}\text { Energy and } \\
\text { industry }\end{array}$} & 4.1 & Reduced hydropower production \\
\hline & 4.2 & $\begin{array}{l}\text { Impaired production/shut down of thermal/nuclear powerplants (due to a lack of } \\
\text { cooling water and/or environmental legislation for discharges into streams) }\end{array}$ \\
\hline & 4.3 & $\begin{array}{l}\text { Restriction/disruption of industrial production process (due to a lack of process water } \\
\text { and/or environmental legislation/restrictions for discharges into streams) }\end{array}$ \\
\hline & 4.4 & Other \\
\hline & 4.5 & Increased costs/economic losses \\
\hline \multirow[t]{4}{*}{$\begin{array}{l}\text { Waterborne } \\
\text { transportation }\end{array}$} & 5.1 & $\begin{array}{l}\text { Impaired navigability of streams (reduction of load, increased need of interim storage } \\
\text { of goods at ports) }\end{array}$ \\
\hline & 5.2 & Stream closed for navigation \\
\hline & 5.3 & Other \\
\hline & 5.4 & Increased costs/economic losses \\
\hline \multirow{6}{*}{$\begin{array}{l}\text { Tourism and } \\
\text { recreation }\end{array}$} & 6.1 & Reduced number of short-stay tourists \\
\hline & 6.2 & Reduced number of long-stay tourists \\
\hline & 6.3 & Sport/recreation facilities affected by a lack of water \\
\hline & 6.4 & Impaired use/navigability of surface waters for water sport activities (including bans) \\
\hline & 6.5 & Other \\
\hline & 6.6 & Increased costs/economic losses \\
\hline
\end{tabular}


Table A2. Continued.

\begin{tabular}{|c|c|c|}
\hline Impact category & Impac & type \\
\hline \multirow[t]{7}{*}{$\begin{array}{l}\text { Public water } \\
\text { supply }\end{array}$} & 7.1 & $\begin{array}{l}\text { Local water supply shortage / problems (drying up of springs/wells, reservoirs, } \\
\text { streams) }\end{array}$ \\
\hline & 7.2 & $\begin{array}{l}\text { Regional/region-wide water supply shortage/problems (drying up of springs/wells, } \\
\text { reservoirs, streams) }\end{array}$ \\
\hline & 7.3 & $\begin{array}{l}\text { Bans on domestic and public water use (e.g., car washing, watering the lawn/garden, } \\
\text { irrigation of sport fields, filling of swimming pools ) }\end{array}$ \\
\hline & 7.4 & $\begin{array}{l}\text { Limitations in water supply to households in rural areas (supply cuts, need to ensure } \\
\text { water supply by emergency actions) }\end{array}$ \\
\hline & 7.5 & $\begin{array}{l}\text { Limitations in water supply to households in urban areas (supply cuts, need to } \\
\text { ensure water supply by emergency actions) }\end{array}$ \\
\hline & 7.6 & Other \\
\hline & 7.7 & Increased costs/economic losses \\
\hline \multirow[t]{13}{*}{ Water quality } & 8.1 & Increased temperature in surface waters (close to or exceeding critical values) \\
\hline & 8.2 & $\begin{array}{l}\text { (Temporary) water quality deterioration/problems of surface waters (natural and } \\
\text { manmade); e.g., significant change of physio-chemical indicators, increased } \\
\text { concentrations of pollutants, decreased oxygen saturation levels, eutrophication, } \\
\text { algal bloom) }\end{array}$ \\
\hline & 8.3 & $\begin{array}{l}\text { (Temporary) impairment of ecological status of surface waters (according to EU } \\
\text { Water Framework Directive) }\end{array}$ \\
\hline & 8.4 & $\begin{array}{l}\text { (Temporary) impairment of chemical status of surface waters (according to EU Water } \\
\text { Framework Directive) }\end{array}$ \\
\hline & 8.5 & Increased salinity of surface waters (saltwater intrusion and estuarine effects) \\
\hline & 8.6 & Problems with groundwater quality \\
\hline & 8.7 & Increased salinity of groundwater \\
\hline & 8.8 & $\begin{array}{l}\text { Problems with drinking water quality (e.g., increased treatment, violation } \\
\text { of standards) }\end{array}$ \\
\hline & 8.9 & Problems with bathing water quality \\
\hline & 8.10 & Problems with irrigation water quality \\
\hline & 8.11 & Problems with water quality for use in industrial production processes \\
\hline & 8.12 & Other \\
\hline & 8.13 & Increased costs/economic losses \\
\hline \multirow{15}{*}{$\begin{array}{l}\text { Freshwater } \\
\text { ecosystems }\end{array}$} & 9.1 & Increased mortality of aquatic species \\
\hline & 9.2 & Increased species concentration near water \\
\hline & 9.3 & Migration and concentration (loss of wildlife in some areas and too many in others) \\
\hline & 9.4 & Increased populations of invasive (exotic) aquatic species \\
\hline & 9.5 & $\begin{array}{l}\text { Observation of adverse impacts on populations of rare/endangered (protected) } \\
\text { riparian species }\end{array}$ \\
\hline & 9.6 & $\begin{array}{l}\text { Observation of adverse impacts on populations of rare/endangered (protected) } \\
\text { species of wetlands }\end{array}$ \\
\hline & 9.7 & Loss of biodiversity (decrease in species diversity) \\
\hline & 9.8 & Danger for or actual violation of minimum flow or environmental flow requirements \\
\hline & 9.9 & Drying up of shallow water areas, weed growth or algae bloom \\
\hline & 9.10 & Drying up of perennial stream sections \\
\hline & 9.11 & Drying up of lakes and reservoirs (which have a habitat function) \\
\hline & 9.12 & (Mid-/long-term) deterioration of wetlands \\
\hline & 9.13 & Irreversible deterioration/loss of wetlands \\
\hline & 9.14 & Other \\
\hline & 9.15 & Increased costs/economic losses \\
\hline
\end{tabular}


Table A2. Continued.

\begin{tabular}{|c|c|c|}
\hline \multirow{2}{*}{$\begin{array}{l}\text { Impact category } \\
\text { Terrestrial } \\
\text { ecosystems }\end{array}$} & \multicolumn{2}{|c|}{ Impact type } \\
\hline & 10.1 & $\begin{array}{l}\text { Increased species mortality (specify species (latin term) and state whether a } \\
\text { rare/endangered/protected species is concerned) }\end{array}$ \\
\hline & 10.2 & Changes in species biology/ecology \\
\hline & 10.3 & Loss of biodiversity (decrease in species diversity) \\
\hline & 10.4 & Shift in species composition \\
\hline & 10.5 & Reduced plant growth \\
\hline & 10.6 & (Mid-/long-term) deterioration of habitats \\
\hline & 10.7 & Irreversible deterioration/loss of habitats \\
\hline & 10.8 & Lack of feed/water for terrestrial wildlife \\
\hline & 10.9 & Increased attacks of pests and diseases \\
\hline & 10.10 & $\begin{array}{l}\text { Increased contact of wild animals under stress (shortage/lack of feed and water) with } \\
\text { humans/human settlements }\end{array}$ \\
\hline & 10.11 & Other \\
\hline & 10.12 & Increased costs/economic losses \\
\hline \multirow[t]{5}{*}{ Soil system } & 11.1 & Drought-related erosion processes (loss of soil fertility) \\
\hline & 11.2 & Structural damage to private property due to soil subsidence/shrinkage \\
\hline & 11.3 & Structural damages on infrastructures due to soil subsidence/shrinkage \\
\hline & 11.4 & Other \\
\hline & 11.5 & Increased costs/economic losses \\
\hline \multirow[t]{4}{*}{ Wildfires } & 12.1 & Increased burned area \\
\hline & 12.2 & Increased number of wildfires \\
\hline & 12.3 & Increased severity of wildfires \\
\hline & 12.5 & Increased costs/economic losses \\
\hline \multirow[t]{3}{*}{ Air quality } & 13.1 & $\begin{array}{l}\text { Air quality pollution effects/problems (dust bowl effect, wildfires, substitution of } \\
\text { hydropower production by fossil energy) }\end{array}$ \\
\hline & 13.2 & Other \\
\hline & 13.3 & Increased costs/economic losses \\
\hline \multirow{6}{*}{$\begin{array}{l}\text { Human health } \\
\text { and public safety }\end{array}$} & 14.1 & Heat stress problems (if drought is associated with a heat wave) \\
\hline & 14.2 & Increased respiratory ailments (heat wave and air quality) \\
\hline & 14.3 & Excess mortality during heat waves \\
\hline & 14.4 & Drought induced public-safety issues (e.g., increased risk of structural damages) \\
\hline & 14.5 & Other \\
\hline & 14.6 & Increased costs/economic losses \\
\hline \multirow[t]{4}{*}{ Conflicts } & 15.1 & Water allocation conflicts - international \\
\hline & 15.2 & Regional/local user conflicts \\
\hline & 15.3 & Other \\
\hline & 15.4 & Increased costs/economic losses \\
\hline
\end{tabular}


Author contributions. Kerstin Stahl, Irene Kohn and Veit Blauhut designed the research. Kerstin Stahl, Irene Kohn, Veit Blauhut, Vanda Acacio, Susana Dias, Julia Urquijo, Lucia De Stefano, Lena M. Tallaksen developed the database structure and impact categorization scheme. All co-authors provided data. Irene Kohn or Veit Blauhut moderated all EDII entries, Veit Blauhut designed the data entry interface, James H. Stagge implemented the online version, Irene Kohn and Veit Blauhut carried out the analyses and created the graphs, maps and tables in the manuscript, Kerstin Stahl, Irene Kohn, Veit Blauhut prepared the manuscript with contributions and review from all co-authors.

Acknowledgements. The work was funded by the EU FP7 project DROUGHT-R\&SPI (contract no. 282769). The following staff and students searched and provided impact reports and/or entered these into the database through the categorization interface: Daniel Eilertz, Barbara Frielingsdorf, Anne Kristina Tvedalen, Trine Jahr Hegdahl, Vassilis Kourentzis, Luigi de Paoli, Lanfranco Senn, Jill Simon and the students of the Projektstudie: Risikomanagement Trockenheit at the University of Freiburg.

Edited by: P. Tarolli

Reviewed by: K. H. Smith and one anonymous referee

\section{References}

Bachmair, S., Kohn, I., and Stahl, K.: Exploring the link between drought indicators and impacts, Nat. Hazards Earth Syst. Sci., 15, 1381-1397, doi:10.5194/nhess-15-1381-2015, 2015.

Blauhut V., Gudmundsson, L., and Stahl, K.: Towards panEuropean drought risk maps: quantifying the link between drought indices and reported drought impacts, Environ. Res. Lett., 10, 014008, doi:10.1088/1748-9326/10/1/014008, 2015a.

Blauhut, V., Stahl, K., and Kohn, I.: The dynamics of vulnerability to drought from an impact perspective, in: Drought: Research and Science-Policy Interfacing, edited by: Andreu, J., Solera, A., Paredes-Arquiola, J., Haro-Monteagudo, D., and van Lanen, H. A. J., CRC Press, London, 349-354, doi:10.1201/b18077-56, $2015 b$.

Bouma, E.: Development of comparable agro-climatic zones for the international exchange of data on the efficacy and crop safety of plant protection products, Bulletin OEPP/EPPO, 35, 233-238, 2005.

Ceglar, A., Medved-Cvikl, B., Morán-Tejeda, E., Vicente Serrano, S. M., and Kajfež-Bogataj, L.: Assessment of multi-scale drought datasets to quantify drought severity and impacts in agriculture: a case study for Slovenia, Int. J. Spat. Data Infrastruct. Res., 7, 464-487, doi:10.2902/1725-0463.2012.07.art21, 2012.

Dessai, S. and Sims, C.: Public perception of drought and climate change in southeast England, Environ. Hazards, 9, 340357, doi:10.3763/ehaz.2010.0037, 2010.

De Stefano, L., Urquijo, J., Acácio, V., Andreu, J., Assimacopoulos, D., Bifulco, C., and Wolters, W.: Policy and drought responses - Case Study scale, DROUGHT-R\&SPI Technical Report No. 4, 115 pp., available at: http://www.eu-drought.org/ technicalreports/10821986/ (last access: 7 February 2016), 2012.
Dieker, E., van Lanen, H. A. J., and Svoboda, M.: Comparison of Three Drought Monitoring Tools in the USA, WATCH Technical Report No. 25, 86 pp., available at: http://www.eu-watch.org/ media/default.aspx/emma/org/10653999/ (last access: 7 February 2016), 2010.

Ding, Y., Hayes, M. J., and Wildham, M.: Measuring economic impacts of drought: a review and discussion, Disaster Prev. Manage., 20, 434-446, doi:10.1108/09653561111161752, 2011.

Estrela, M. J., Peñarrocha, D., and Millán, M.: Multi-annual drought episodes in the Mediterranean (Valencia region) from 19501996. A spatio-temporal analysis, Int. J. Climatol., 20, 15991618, doi:10.1002/1097-0088, 2000.

European Commission: Communication from the Commission to the European Parliament and the Council, the European Economic and Social Committee and the Committee of the Regions: A Blueprint to Safeguard Europe's Water Resources (COM (2012) 0673 Final), available at: http://eur-lex.europa. eu/legal-content/EN/TXT/?uri=CELEX:52012DC0673 (last access: 7 February 2016), 2012.

European Environment Agency: Safe water and healthy water services in a changing environment, EEA Technical Report 7/2011, 33 pp., Publications Office of the European Union, Luxembourg, doi:10.2800/78043, 2011.

European Environment Agency: Water resources in Europe in the context of vulnerability, EEA 2012 state of water assessment, EEA Report No. 11/20122, Publications Office of the European Union, Luxembourg, 92 pp., doi:10.2800/65298, 2012.

Folland, C. K., Hannaford, J., Bloomfield, J. P., Kendon, M., Svensson, C., Marchant, B. P., Prior, J., and Wallace, E.: Multiannual droughts in the English Lowlands: a review of their characteristics and climate drivers in the winter half-year, Hydrol. Earth Syst. Sci., 19, 2353-2375, doi:10.5194/hess-19-23532015, 2015.

Gil, M., Garrido, A., and Hernández-Mora, N.: Direct and indirect economic impacts of drought in the agri-food sector in the Ebro River basin (Spain), Nat. Hazards Earth Syst. Sci., 13, 26792694, doi:10.5194/nhess-13-2679-2013, 2013.

Hannaford, J., Lloyd-Hughes, B., Keef, C., Parry, S., and Prudhomme, C.: Examining the large-scale spatial coherence of European drought using regional indicators of precipitation and streamflow deficit, Hydrol. Process., 25, 1146-1162, doi:10.1002/hyp.7725, 2011.

Hayes, M., Svoboda, M., Wall, N., and Widhalm, M.: The Lincoln declaration on drought indices: universal meteorological drought index recommended, B. Am. Meteorol. Soc., 92, 485488, doi:10.1175/2010BAMS3103.1, 2011.

Kallis, G.: Droughts, Ann. Rev. Environ. Resour., 33, 85-118, doi:10.1146/annurev.environ.33.081307.123117, 2008.

Knight, C. G., Reav, I., and Staneva, M. P. (Eds.): Drought in Bulgaria: A Contemporary Analog for Climate Change, Ashgate Publishing, Aldershot, 336 pp., 2004.

Knutson, C. L., Hayes, M. J., and Philipps, T.: How to Reduce Drought Risk, Western Drought Coordination Council, Preparedness and Mitigation Working Group, Lincoln, 10 pp., available at: http://drought.unl.edu/portals/0/docs/risk.pdf (last access: 7 February 2016), 1998.

Kossida, M., Kakava, A., Tekidou, A., and Mimikou, M.: Vulnerability to Water Scarcity and Drought in Europe, ETC/ICM Technical Report 3/2012, European Topic Centre 
on Inland, Coastal and Marine Waters (ETC/ICM), Prague, 102 pp., available at: http://icm.eionet.europa.eu/ETC_Reports/ VulnerabilityToWaterScarcityAndDroughtInEurope (last access: 7 February 2016), 2012.

Lackstrom, K., Brennan, A., Ferguson, D., Crimmins, M., Darby, L., Dow, K., Ingram, K., Meadow, A., Reges, H., Shafer, M., and Smith, K.: The Missing Piece: Drought Impacts Monitoring. Workshop report produced by the Carolinas Integrated Sciences \& Assessments program and the Climate Assessment for the Southwest, 5-6 March 2013, Tucson, AZ, 1-23, 22 pp., 2013.

Lloyd-Hughes, B.: A spatio-temporal structure-based approach to drought characterisation, Int. J. Climatol., 32, 406-418, doi:10.1002/joc.2280, 2012.

Logar, I. and van den Bergh, J. C.: Methods to assess costs of drought damages and policies for drought mitigation and adaptation: review and recommendations, Water Resour. Manage., 27, 1707-1720, doi:10.1007/s11269-012-0119-9, 2013.

Musolino, D., Massarutto, A., and De Carli, A.: Ex-post evaluation of the socio-economic impacts of drought in some areas in Europe, in: Drought: Research and Science-Policy Interfacing, edited by: Andreu, J., Solera, A., Paredes-Arquiola, J., HaroMonteagudo, D., and van Lanen, H. A. J., CRC Press, London, 71-77, doi:10.1201/b18077-56, 2015.

Parry, S., Prudhomme, C., Wilby, R., and Wood, P.: Chronology of drought termination for long records in the Thames catchment, in: Drought: Research and Science-Policy Interfacing, edited by: Andreu, J., Solera, A., Paredes-Arquiola, J., Haro-Monteagudo, D., and van Lanen, H. A. J., CRC Press, London, 165-170, doi:10.1201/b18077-56, 2015.

Sepulcre, G., Horion, S. M. A. F., Singleton, A., Carrao, H., and Vogt, J.: Development of a Combined Drought Indicator to detect agricultural drought in Europe, Nat. Hazards Earth Syst. Sci., 12, 3519-3531, doi:10.5194/nhess-12-3519-2012, 2012.

Smakhtin, V. U. and Schipper, E. L.: Droughts: The impact of semantics and perceptions, Water Policy, 10, 131-143, doi:10.2166/wp.2008.036, 2008.

Stagge, J. H., Tallaksen, L. M., Kohn, I., Stahl, K., and van Loon, A. F.: A European Drought Reference (EDR) Database: design and Online Implementation, DROUGHT-R\&SPI Technical Report No. 12, 42 pp., available at: http://www.eu-drought.org/ technicalreports/10832306/ (last access: 7 February 2016), 2013.

Stagge, J. H., Kohn, I., Tallaksen, L. M., and Stahl, K.: Modeling drought impact occurrence based on climatological drought indices for Europe, J. Hydrol.,530, 37-50, doi:10.1016/j.jhydrol.2015.09.039, 2015.

Stahl, K., Blauhut, V., Kohn, I., Acácio, V., Assimacopoulos, D., Bifulco, C., De Stefano, L., Dias, S., Eilertz, D., Frielingsdorf, B., Hegdahl, T. J., Kampragou, E., Kourentzis, V., Melsen, L., van Lanen, H. A. J., Van Loon, A. F., Massarutto, A., Musolino, D., de Paoli, L., Senn, L., Stagge, J. H., Tallaksen, L. M., and Urquijo, J.: A European Drought Impact Report Inventory (EDII): Design and Test for Selected Recent Droughts in Europe, DROUGHT-R\&SPI Technical Report No. 3, 23 pp., available at: http://www.eu-drought.org/technicalreports/10814306/ (last access: 7 February 2016), 2012.

Stahl K., Blauhut, V., Kohn, I., De Stefano, L., Dias, S., Urquijo, J., Tallaksen, L. M., Van Lanen, H. A. J., and Wolters, W.: Stakeholder views on drought impacts and Drought Risk Maps at the Pan-European scale: results from the 2nd Pan-European
Drought Dialogue Forum, DROUGHT-R\&SPI Technical Report No. 17, available at: http://www.eu-drought.org/technicalreports/ 10850944/ (last access: 7 February 2016), 2014.

Stahl, K., Kohn, I., De Stefano, L., Tallaksen, L. M., Rego, F.C., Seneviratne, S. I., Andreu, J., and van Lanen, H. A. J.: An impact perspective on pan-European drought sensitivity, in: Drought: Research and Science-Policy Interfacing, edited by: Andreu, J., Solera, A., Paredes-Arquiola, J., Haro-Monteagudo, D., and van Lanen, H. A. J., CRC Press, London, 329-334, doi:10.1201/b18077-56, 2015.

Steinemann, A.: Drought Information for Improving Preparedness in the Western States, B. Am. Meteorol. Soc., 95, 843-847, doi:10.1175/BAMS-D-13-00067.1, 2014.

Tallaksen, L. M. and Stahl, K.: Spatial and temporal patterns of large-scale droughts in Europe: model dispersion and performance, Geophys. Res. Lett., 41, 429-434, doi:10.1002/2013GL058573, 2014.

Tánago, I. G., Ballesteros, M., Urquijo, J., and De Stefano, L.: Exploring situations of vulnerability to drought from a sectorial perspective: A starting point for regional assessments, in: Drought: Research and Science-Policy Interfacing, edited by: Andreu, J., Solera, A., Paredes-Arquiola, J., Haro-Monteagudo, D., and van Lanen, H. A. J., CRC Press, London, 341-348, doi:10.1201/b18077-56, 2015.

UN/ISDR: Drought Risk Reduction, Framework and Practices, Contributing to the Implementation of the Hyogo Framework for Action, United Nations secretariat of the International Strategy for Disaster Reduction (UNISDR), Geneva, 213 pp., 2009.

Van Lanen, H. A. J., Tallaksen, L. M., Stahl, K., Assimacopoulos, D., Wolters, W., Andreu, J., Rego, F., Seneviratne, S. I., De Stefano, L., Massarutto, A., Garnier, E., and Seidl, I.: Fostering Drought Research and Science-Policy Interfacing: Achievements of the DROUGHT-R\&SPI project, in: Drought: Research and Science-Policy Interfacing, edited by: Andreu, J., Solera, A., Paredes-Arquiola, J., Haro-Monteagudo, D., and van Lanen, H. A. J., CRC Press, London, 3-12, doi:10.1201/b18077-56, 2015.

Van Loon, A. F. and Van Lanen, H. A. J.: A process-based typology of hydrological drought, Hydrol. Earth Syst. Sci., 16, 19151946, doi:10.5194/hess-16-1915-2012, 2012.

Van Loon, A. F., Ploum, S. W., Parajka, J., Fleig, A. K., Garnier, E., Laaha, G. and Van Lanen, H. A. J.: Hydrological drought types in cold climates: quantitative analysis of causing factors and qualitative survey of impacts, Hydrol. Earth Syst. Sci., 19, 1993-2016, doi:10.5194/hess-19-1993-2015, 2015.

Wilhite, D. A.: Reducing societal vulnerability to drought, in: Drought: A Global Assessment II, edited by: Wilhite, D. A., Routledge, New York, London, 295-298, 2000.

Wilhite, D. A. and Glantz, M. H.: Understanding the drought phenomenon: the role of definitions, Water Int., 10, 111-120, doi:10.1080/02508068508686328, 1985.

Wilhite, D. A. and Vanyarkho, O.: Pervasive impacts of a creeping phenomenon, in: Drought: A Global Assessment I, edited by: Wilhite, D. A., Routledge, New York, London, 245-255, 2000.

Wilhite, D. A., Svoboda, M. D., and Hayes, M. J.: Understanding the complex impacts of drought: A key to enhancing drought mitigation and preparedness, Water Resour. Manage., 21, 763-774, doi:10.1007/s11269-006-9076-5, 2007. 